\title{
Morphometric studies on ovarian follicles and corpora lutea during the oestrous cycle in the mouse*
}

\author{
A. Numazawa and S. Kawashima $†$ \\ Zoological Institute, Faculty of Science, University of Tokyo, Bunkyo-ku, Tokyo 113, and \\ $†$ Zoological Laboratory, Faculty of Science, Hiroshima University, Hiroshima 730, Japan
}

\begin{abstract}
Summary. The $\mathrm{C} 3 \mathrm{H} / \mathrm{Tw}$ mice were those showing regular 5-day cycles. A population of small follicles (100-149 $\mu \mathrm{m}$ in diameter) started growing at oestrus, but the majority underwent atresia during metoestrus, dioestrus and pro-oestrus. The remaining healthy follicles continued to grow during the next cycle, although several large ones eventually became atretic and failed to ovulate. Finally about 10 follicles survived and attained the preovulatory stage, measuring more than $400 \mu \mathrm{m}$ in diameter by the time of the ovulatory surge of gonadotrophins. Two oestrous cycles, i.e. about 10 days, are therefore required for small follicles to complete their growth until ovulation.

At oestrus, atretic follicles bearing oocytes in the resting phase were rarely encountered, showing that few follicles underwent atresia at this stage. Smaller atretic follicles, 100-199 $\mu \mathrm{m}$ in diameter, were numerous at metoestrus, while larger ones, 250-399 $\mu \mathrm{m}$, increased in number during dioestrus 1 and dioestrus 2. Corpora lutea took 4 successive oestrous cycles from the time of formation to complete disintegration.
\end{abstract}

\section{Introduction}

In rodents, the changes in number and size of ovarian follicles in response to follicle-stimulating hormone (FSH) and luteinizing hormone (LH) during the oestrous cycle have been well documented (Mandl \& Zuckerman, 1952; Pedersen, 1970; Moore \& Greenwald. 1974: Richards. 1975, 1980; Hirshfield \& Midgley, 1978a). The growth of follicles is associated with the blood concentrations of the gonadotrophins and ovarian steroids and a large number of follicles is destined to undergo atresia before attaining full maturation. The purpose of the present investigation was to study quantitatively the morphological changes in healthy and atretic follicles and corpora lutea (CL) during the oestrous cycle in the mouse.

\section{Materials and Methods}

Female mice of the $\mathrm{C} 3 \mathrm{H} / \mathrm{Tw}$ strain were used. The animals were kept at $25^{\circ} \mathrm{C}$, the daily light cycle being $12 \mathrm{~h} \mathrm{light} / 24 \mathrm{~h}$ (lights on at 06:00 h). Daily vaginal smears were taken between 10:00 and 12:00 h for 2 weeks beginning when the animals were 2 months old. Only those exhibiting regular, 5-day oestrous cycles were used. On each day of the cycle. 4 mice were killed by an overdose of ether between 13:00 and 14:00 h. Ovaries were removed, fixed in Bouin's

* Reprint requests to Dr S. Kawashima. 
fluid, embedded in paraplast, serially sectioned at $7 \mu \mathrm{m}$ and stained with Meyer's haematoxylin and eosin.

The largest diameter of a follicle or corpus luteum appearing in serial sections and another one at right angles to it were measured by a calibrated ocular micrometer; the mean of the two values was taken as the diameter. Volumes of follicles and $C L$ were obtained on the basis of the mean diameter; e.g. for follicles with a diameter of $200-249 \mu \mathrm{m}$, the volume was calculated from:

$$
\bar{v}_{200-249}=\frac{\sum_{i=1}^{N}\left[\frac{4}{3} \pi\left(\frac{\bar{d}_{200-249}}{2}\right)^{3} n_{i}\right]}{N}
$$

where $N=$ the number of mice; $n_{i}=$ the number of follicles or CL in both ovaries, and $\bar{d}=$ the mean diameter.

The numbers of follicles or CL in both ovaries were counted in serial sections and histograms of the frequency distributions of size at $50 \mu \mathrm{m}$ intervals of diameter were prepared. To prevent counting any component more than once camera lucida drawings were made of every fifth section. A comparison of our classification with that of Pedersen (1970) is shown in Text-fig. 1. Healthy follicles $>100 \mu \mathrm{m}$ in diameter, without any indication of atresia (Pl. 1, Fig. 1), were counted, but those measuring $<100 \mu \mathrm{m}$ in diameter were not. Atretic follicles $>100 \mu \mathrm{m}$ in diameter, with granulosa cells bearing pycnotic nuclei were counted. Atretic follicles usually had different amounts of cell debris in the antrum and the oocytes were sometimes dividing parthenogenetically. Ten stages were distinguished in the oocytes of atretic follicles: the resting phase or dictyotene (PI. 1, Fig. 2), diakinesis, first metaphase, first anaphase, (Pl. 1, Fig. 3), first polar body phase, second prophase, second metaphase, second anaphase, second polar body

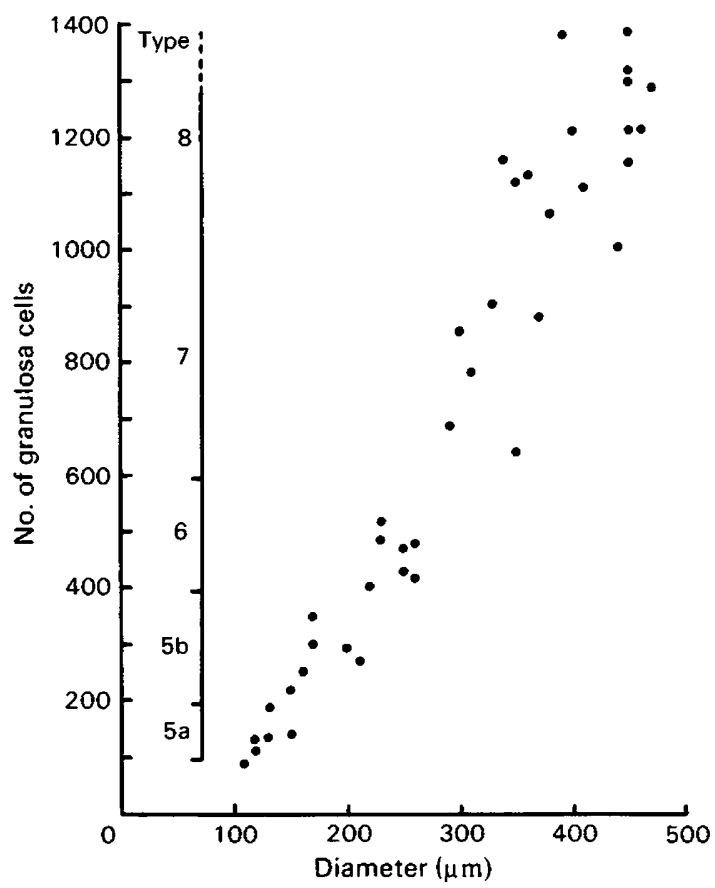

Text-fig. 1. The correlation between mean diameter (present study) and the number of granulosa cells appearing in largest cross sections of some healthy follicles, with reference to the criteria of Pedersen (1970). 
phase, and so-called 'morula'. Corpora lutea measuring $>200 \mu \mathrm{m}$ in diameter and clearly distinguishable from the rest of the ovarian tissues were counted. Degenerating CL were strongly eosinophilic.

Statistical comparisons of the numbers of follicles or CL at different stages of the oestrous cycle were carried out using Student's $t$ test. The distribution patterns of volumes of follicles and CL were analysed by Kolmogorov-Smirnov's two-sample test. Correlation coefficients between the numbers of healthy and atretic follicles were tested by $F$ test. The ratios of the oocytes in the resting phase to those in the other phases of the meiotic division were compared by $\chi^{2}$ tests.

\section{Results}

\section{Healthy and atretic follicles}

Changes in size distribution of healthy follicles during the oestrous cycle are shown in Text-fig. 2. The fully grown preovulatory follicles measuring more than $400 \mu \mathrm{m}$ in diameter were distinguished from smaller follicles on the day of pro-oestrus. The newly formed corpora lutea were comparable in number (about 10) with the preovulatory follicles which had existed at pro-oestrus (Text-fig. 5). The sudden disappearance of fully grown preovulatory follicles between pro-oestrus and oestrus is clearly demonstrated in histograms showing volume change in follicles (Text-fig. 2). Meanwhile, smaller follicles, 100-349 $\mu \mathrm{m}$ in diameter, increased in number at oestrus due to the growth of the primary or secondary follicles $(<100 \mu \mathrm{m}$ in diameter $)$. Although some of these follicles continued to grow during metoestrus and through pro-oestrus, growing follicles decreased in total number and many underwent atresia during this period (total number of follicles $>100 \mu \mathrm{m}$ in diameter was $234 \pm 24 \cdot 2 /$ mouse at metoestrus and $156 \pm 8 \cdot 1 /$ mouse at pro-oestrus, $P<0.01$, Student's $t$ test).

Large atretic follicles with a diameter of $>350 \mu \mathrm{m}$ appeared in the second half of the oestrous cycle (dioestrus 1 and 2 ) and at the subsequent pro-oestrus, but the follicles of this size were greatly decreased in number during oestrus and metoestrus (Text-fig. 1). Atretic follicles of 250-349 $\mu \mathrm{m}$ in diameter also showed a similar pattern of changes. The atretic follicles of $100-149 \mu \mathrm{m}$ in diameter were most numerous in the ovaries irrespective of the stage of the oestrous cycle. However, the pattern of volume distribution showed that the atretic follicles of the largest volume were those measuring 200-299 $\mu \mathrm{m}$ in diameter (Text-fig. 2). The difference in volume distribution of the atretic follicles between metoestrus and dioestrus 2 was statistically significant $(P<0.01$, Kolmogorov-Smirnov's two-sample test), suggesting that the follicles $>250 \mu \mathrm{m}$ undergo atresia during the second half of the oestrous cycle and the next pro-oestrus.

Relationships between the healthy and atretic follicles of different sizes are shown in Text-fig. 3. The healthy follicles of various sizes $(100-399 \mu \mathrm{m}$ in diameter) invariably increased in number between oestrus and metoestrus. The difference in number between oestrus-metoestrus and pro-oestrus was always statistically significant for the healthy follicles $>150 \mu \mathrm{m}$ in diameter $(P<0.01$, Student's $t$ test) but not for those measuring 100-149 $\mu \mathrm{m}$ in diameter. Larger atretic follicles of $250-349 \mu \mathrm{m}$ in diameter were more numerous at dioestrus 2 and pro-oestrus than at oestrus and metoestrus (Text-fig. 3). The changes in number of the healthy and atretic follicles of 250-299 $\mu \mathrm{m}$ were inversely related (correlation coefficient: $r=-0.893, P<0.05$, F test). The atretic follicles of 100-199 $\mu \mathrm{m}$ were most frequently encountered at metoestrus $(P<0.05$, Student's $t$ test, compared with oestrus). However, no reduction in number of the healthy follicles of this size took place at metoestrus, suggesting a rapid shrinkage of follicles undergoing atresia (see Text-fig. 4).

The relationships between the diameter of all atretic follicles measuring more than $200 \mu \mathrm{m}$ and the stages of oocytes dividing parthenogenetically in the atretic follicles at different stages of the oestrous cycle are shown in Text-fig. 4. The atretic follicles $<200 \mu \mathrm{m}$ in diameter were too numerous to count. At oestrus, oocytes in the resting phase, bearing the intact germinal vesicles, 


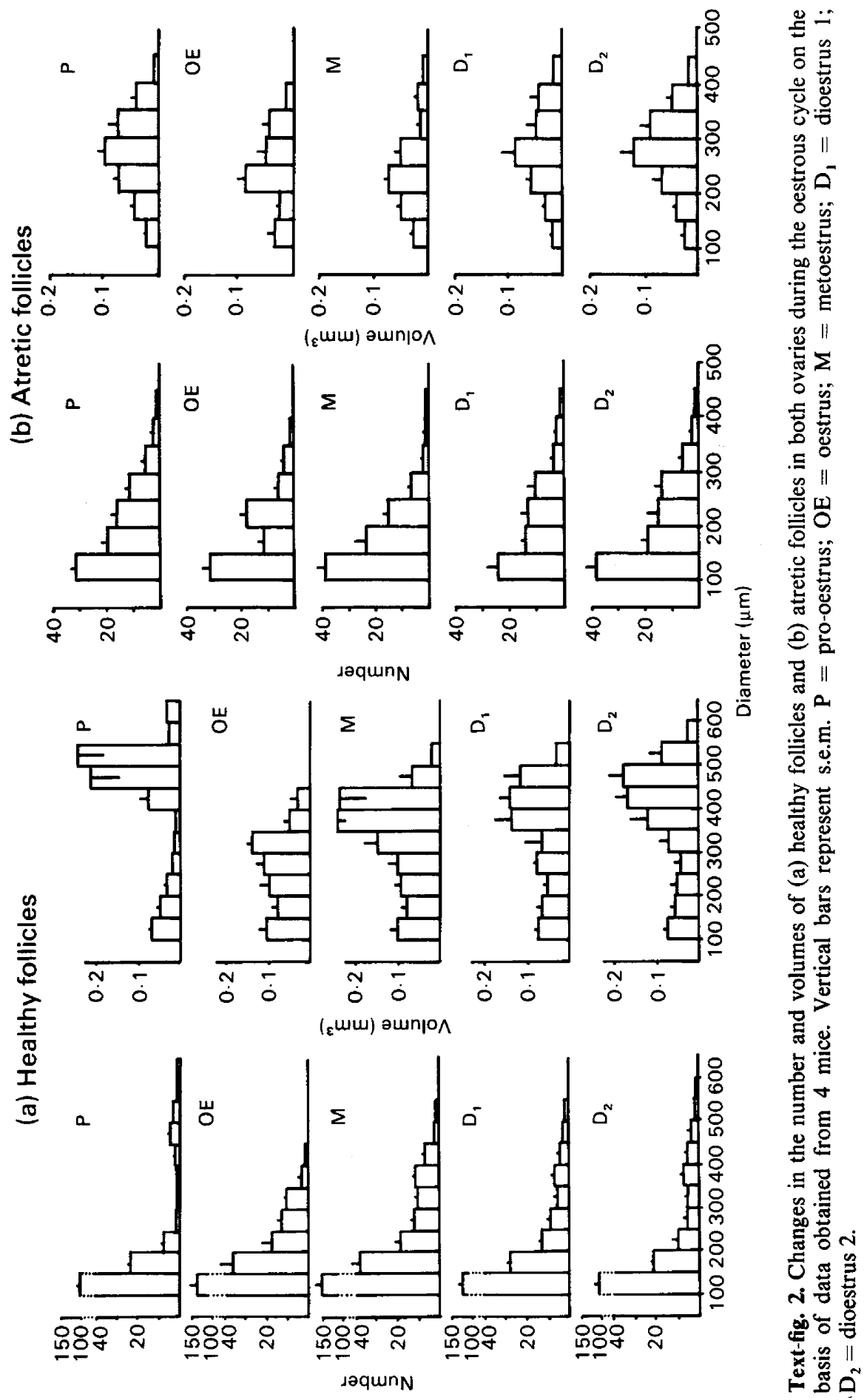




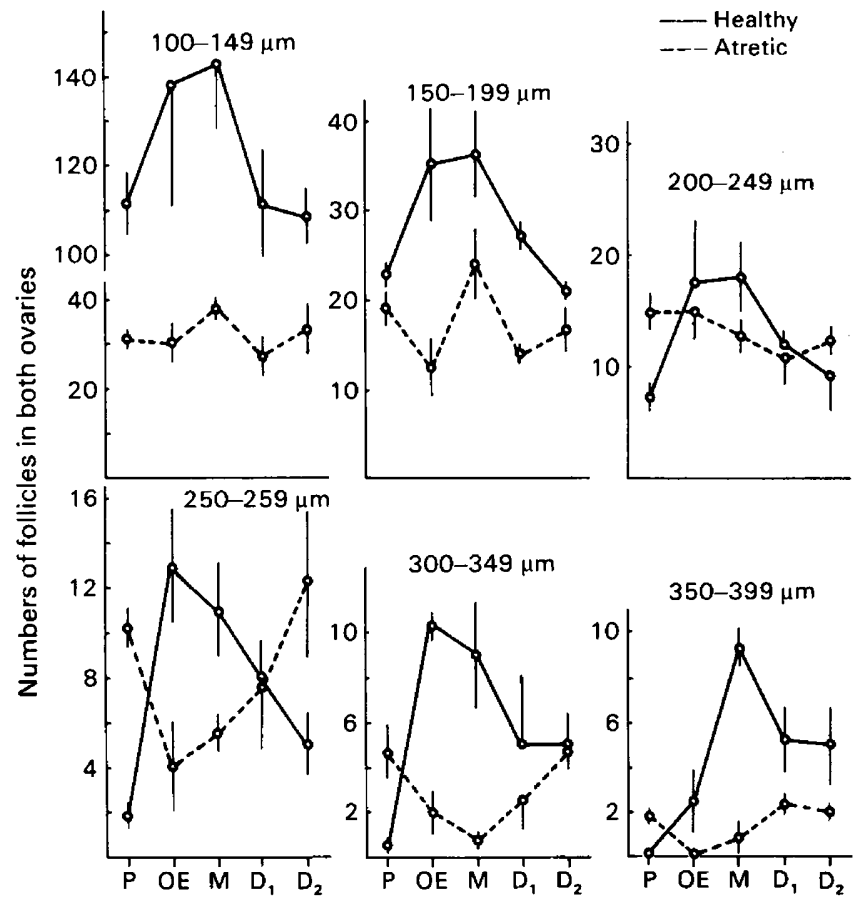

Text-fig. 3. Changes in the number of healthy and atretic follicles in both ovaries during the mouse oestrous cycle. $P=$ pro-oestrus; $O E=$ oestrus; $M=$ metoestrus; $D_{1}=$ dioestrus 1 ; $D_{2}=$ dioestrus 2 .

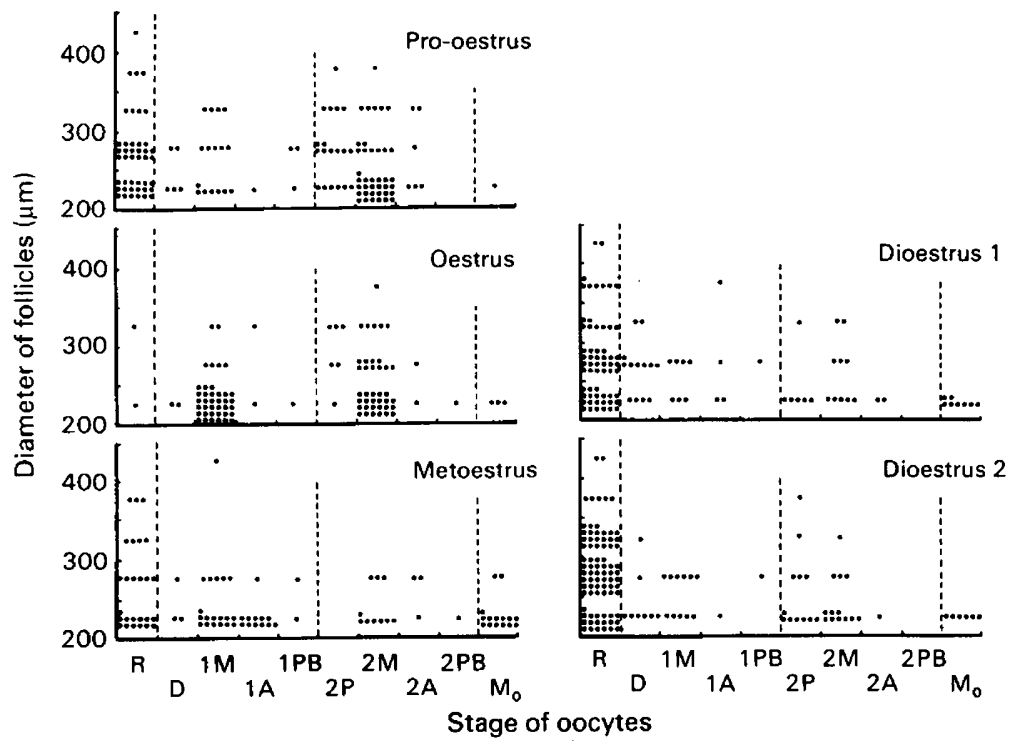

Text-fig. 4. Relationship between mean diameter of atretic follicles and stages of oocytes during the oestrous cycle. All atretic follicles $>200 \mu \mathrm{m}$ in diameter in both ovaries of 4 mice were counted. Each point depicts one oocyte. $\mathrm{R}=$ resting phase (dictyotene); $\mathrm{D}=$ diakinesis; $1 \mathrm{M}=1$ st metaphase; $1 \mathrm{~A}=1 \mathrm{st}$ anaphase; $1 \mathrm{~PB}=1$ st polar body; $2 \mathrm{P}=2 \mathrm{nd}$ prophase; $2 \mathrm{M}=2 \mathrm{nd}$ metaphase; $2 \mathrm{~A}=2 \mathrm{nd}$ anaphase; $2 \mathrm{~PB}=2 \mathrm{nd}$ polar body; $\mathrm{Mo}=$ 'morula' or cytolytic. 
were seldom encountered, while the oocytes undergoing the first or the second meiotic division were numerous. However, many new atretic follicles with oocytes still in the resting phase appeared during metoestrus to the next pro-oestrus. Oocytes at the stage of the first and the second meiotic division decreased in number during the period from metoestrus to dioestrus 2 (ratios of the number of oocytes undergoing the meiotic division to that in the resting phase were $92 / 2$ at oestrus and $140 / 163$ from metoestrus through dioestrus $2 ; \chi^{2}=78 \cdot 6, P<0 \cdot 01$ ). At pro-oestrus, although the oocytes in the resting phase decreased in number as compared to those at dioestrus 2 , the oocytes in the second meiotic division increased in number. The oocytes in the resting phase were decidedly less numerous in the atretic follicles $>350 \mu \mathrm{m}$ than in those measuring $<350 \mu \mathrm{m}$ throughout the oestrous cycle. The ratio of the oocytes undergoing 1st or 2nd meiotic division in the atretic follicles $>350 \mu \mathrm{m}$ to those in the atretic follicles measuring $200-349 \mu \mathrm{m}$ was significantly smaller than the ratio of the oocytes in the resting phase in follicles of these sizes $\left(6 / 221\right.$ and $23 / 187$, respectively; $\left.\chi^{2}=11.99, P<0.01\right)$. These results indicate that atretic follicles containing an oocyte still bearing an intact germinal vesicle were produced from healthy follicles of any size, including large preovulatory ones. When the germinal vesicles of the oocytes later broke down and the meiotic division proceeded, the atretic follicles became reduced in size.

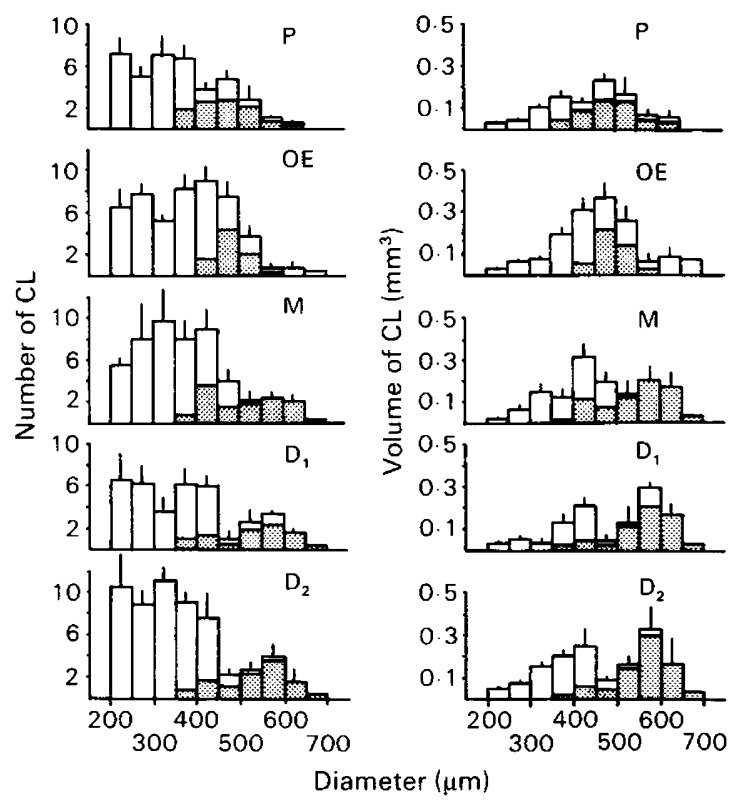

Text-fig. 5. Changes in diameters and volume of corpora lutea in both ovaries during the oestrous cycle on the basis of data obtained from 4 mice. Shaded columns represent newly formed corpora lutea. Vertical bars represent s.e.m. $\mathrm{P}=$ pro-oestrus; $\mathrm{OE}=$ oestrus; $\mathbf{M}=$ metoestrus; $\mathrm{D}_{1}=$ dioestrus $1 ; \mathrm{D}_{2}=$ dioestrus 2 .

\section{PLATE 1}

Mouse follicles of 200-249 $\mu \mathrm{m}$ in diameter at metoestrus. $\times 220$.

Fig. 1. Healthy follicle with the oocyte at the resting phase. Arrows indicate mitotic figures in the granulosa cells. No pycnosis is visible.

Fig. 2. Follicle in early stage of atresia. Arrows indicate granulosa cells bearing pycnotic nuclei. The oocyte is at the resting phase.

Fig. 3. Atretic follicle with oocyte at first metaphase. 
PLATE 1
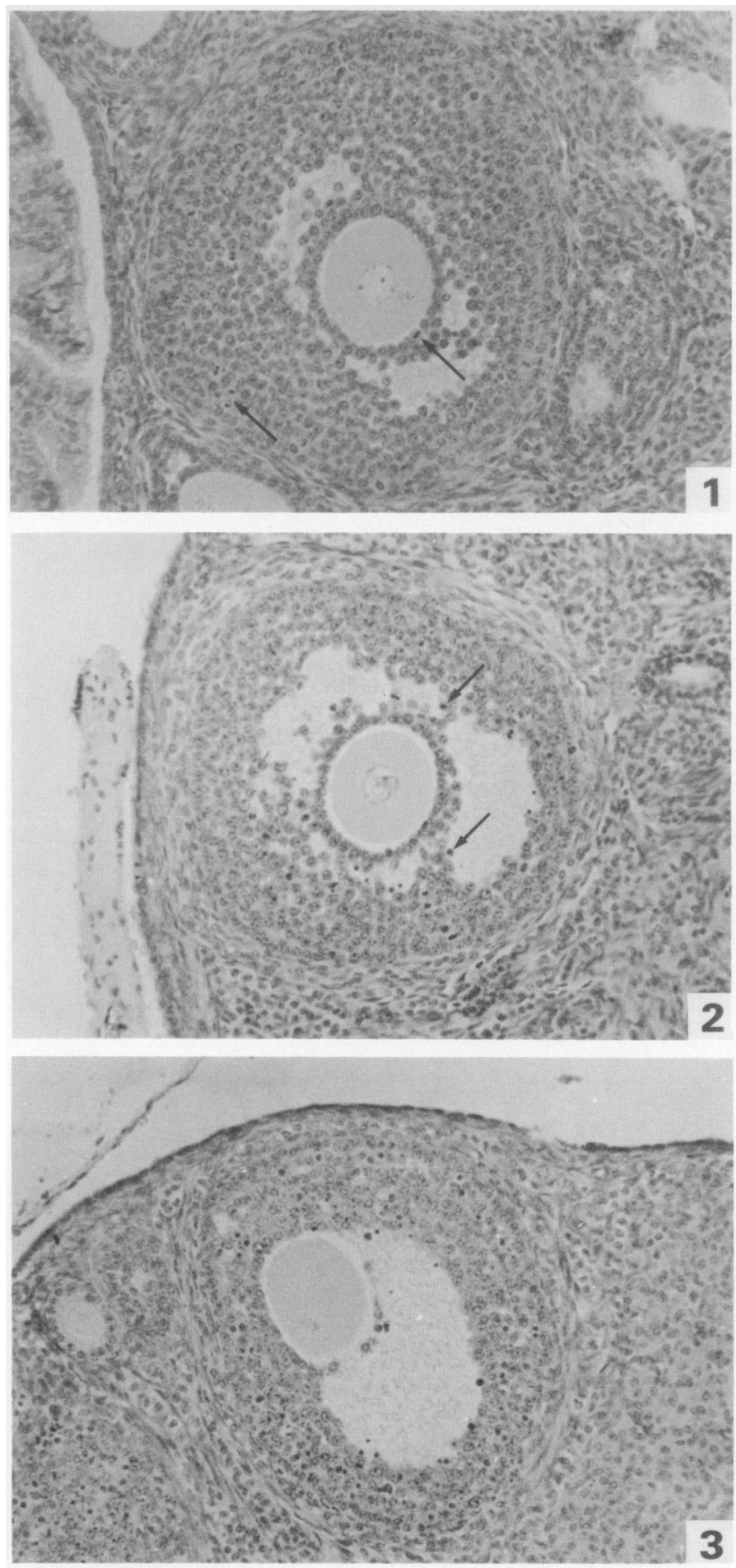

(Facing p. 280) 


\section{Corpora lutea}

The changes in number and volume of corpora lutea (CL) are shown in Text-fig. 5. Newly formed CL were distinguished from old ones by their weaker affinity for eosin and smaller size of lutein cells. Newly formed CL measured $400-600 \mu \mathrm{m}$ in diameter at oestrus and 350-700 $\mu \mathrm{m}$ at metoestrus. The volume distribution of the newly formed CL was significantly different at metoestrus from that at oestrus $(P<0.01$, Kolmogorov-Smirnov's two-sample test), suggesting that only some of the newly formed CL grew during metoestrus, the rest remaining unchanged in size. The differences in volume distribution among these CL at metoestrus, dioestrus 1 and dioestrus 2 were not significant. By contrast, the volume distribution pattern of newly formed CL at dioestrus 2 was significantly different from that at pro-oestrus $(P<0.01$, KolmogorovSmirnov's two-sample test). The findings suggest that the newly formed CL begin to regress during dioestrus 2 through pro-oestrus. Although the difference in number between smaller degenerating $C L<400 \mu \mathrm{m}$ in diameter at dioestrus 1 and dioestrus 2 or at dioestrus 2 and pro-oestrus was not significant statistically, the difference in volume of these CL between dioestrus 1 and dioestrus 2 was statistically significant (total volume of $\mathrm{CL}$ measuring between 200 and $400 \mu \mathrm{m}$ in diameter, $P<0.05$, Student's $t$ test).

\section{Discussion}

Morphometric analysis of follicular development in the ovary during the oestrous cycle has been carried out by several investigators (mouse: Pedersen, 1970; rat: Hirshfield \& Midgley, 1978a), who reported that, although no marked change took place in the number of preantral follicles throughout the oestrous cycle, the antral follicles fluctuated in number with the progress of the cycle. The present study demonstrated that the healthy follicles $<400 \mu \mathrm{m}$ in diameter increased in number at oestrus and decreased at dioestrus 1 through pro-oestrus, while atretic follicles $>$ $250 \mu \mathrm{m}$ in diameter increased during dioestrus 1 through pro-oestrus. The preovulatory follicles $(>400 \mu \mathrm{m})$ increased in number from metoestrus through pro-oestrus and markedly decreased at oestrus; the number of large preovulatory follicles present at metoestrus-pro-oestrus was approximately the same as the number of $\mathrm{CL}$ formed at oestrus.

Atretic follicles with intact germinal vesicles in the oocytes were least numerous at oestrus, while those with oocytes undergoing meiotic division were relatively numerous. The meiotic division of the oocyte in the atretic follicle may be associated with the disappearance of a meiotic inhibitor which occurs in healthy growing follicles (Tsafriri, Pomerantz \& Channing, 1976). At metoestrus, smaller follicles, $100-199 \mu \mathrm{m}$ in diameter, underwent atresia more frequently than at the other stages of the oestrous cycle. In the rat, Hirshfield \& Midgley (1978a) reported that atresia of small follicles occurred most frequently at metoestrus. Engle (1929) found that the total number of atretic follicles and the oocytes bearing 'pseudomaturation spindles' in the atretic follicles attained a peak at metoestrus in the mouse. On the basis of pulse-labelling studies using $\left[{ }^{3} \mathrm{H}\right]$ thymidine, Byskov (1974) also indicated that large atretic follicles appeared at pro-oestrus and rapidly degenerated within the next few days. In the present studies, the number of atretic follicles of $250-299 \mu \mathrm{m}$ in diameter was inversely related to the number of the healthy follicles of this size, but the rapid shrinkage of atretic follicles must have an effect on this relationship. The present finding that large atretic follicles $(250-399 \mu \mathrm{m})$ increased in number from dioestrus 1 through pro-oestrus is in agreement with the conclusions of Mandl \& Zukerman (1952) and Hirshfield \& Midgley (1978a).

The present studies indicate that healthy follicles measuring 100-149 $\mu \mathrm{m}$ in diameter continue to grow to attain $200-400 \mu \mathrm{m}$ at oestrus (Text-fig. 2). Therefore, a period of about 10 days, i.e. two successive oestrous cycles, is required for small follicles of about 100-149 $\mu \mathrm{m}$ in diameter to grow to reach the ovulatory size. The present results agreed well with the findings of 
Pedersen (1970) that the transit time required for type 5a follicles (i.e. having 101-200 granulosa cells and 100-149 $\mu \mathrm{m}$ diameter) to grow to ovulatory size (type 8,>400 $\mu \mathrm{m}$ ) needed two oestrous cycles. During this follicular maturation, the germinal vesicles of the oocytes in the follicles destined to ovulate do not break down until the follicles are exposed to the final gonadotrophin surge (Tsafriri \& Kraicer, 1972; unpublished observations). Hirshfield \& Midgley (1978b) showed that administration of FSH 1 day ahead of the endogenous surge of gonadotrophins caused the precocious appearance of a population of small antral follicles in the rat. Murr, Geschwind \& Bradford (1973) in mice and Moore \& Greenwald (1974) in hamsters also reported that the elevation in serum FSH levels at pro-oestrus and oestrus was responsible for the following development of follicles. The influx of small antral follicles normally occurring at oestrus in the rat was prevented by administration of barbiturate (Hirshfield \& Midgley, 1978a) or FSH antisera (Schwartz, 1974; Welschen \& Dullaart, 1976). Since serum levels of FSH during the second half of the cycle are relatively low (Murr et al., 1973), the reduction in numbers of atretic follicles to a nadir at oestrus may be due to elevated FSH levels at this stage of the cycle. Induction of atresia in growing follicles by depressed serum levels of FSH has been suggested by Schwartz (1974), Richards (1975) and Hirshfield \& Midgley (1978a).

Some of the CL formed at oestrus continued to grow during metoestrus but thenceforth showed no further changes until dioestrus 2 . At the following pro-oestrus, they began to regress and at oestrus were histologically distinguishable from the newly formed set of CL. The degenerating $\mathrm{CL}$, measuring $<400 \mu \mathrm{m}$ in diameter, temporarily increased in total volume at dioestrus 2. This increase may be caused by an elevation in serum levels of prolactin at dioestrus 2 (Yanai \& Nagasawa, 1974). At pro-oestrus, the total number of CL in the ovaries was almost always 40 , and at oestrus about 10 new CL were formed. Accordingly, about $10 \mathrm{CL}$ should disappear during one oestrous cycle, disintegrating into the interstitial tissues, and CL must regress over about 4 cycles.

We thank Professor Emeritus K. Takewaki and Professor K. Ueda, University of Tokyo, for their valuable discussions. This work was supported in part by a Grant-in-Aid for Scientific Research from the Ministry of Education, Science and Culture of Japan and by Life Science Grant-in-Aid from the Institute of Physical and Chemical Research to S.K.

\section{References}

Byskov, A.G.S. (1974) Cell kinetic studies of follicular atresia in the mouse ovary. J. Reprod. Fert. 37, $277-285$.

Engle, E.T. (1929) A quantitative study of follicular atresia in the mouse. Am. J. Anat. 39, 187-203.

Hirshfield, A.N. \& Midgley, A.R., Jr (1978a) Morphometric analysis of follicular development in the rat. Biol. Reprod. 19, 597-605.

Hirshfield, A.N. \& Midgley, A.R. Jr (1978b) The role of FSH in the selction of large ovarian follicles in the rat. Biol. Reprod. 19, 606-611.

Mand, A.M. \& Zuckerman, S. (1952) Cyclical changes in the number of medium and large follicles in the adult rat ovary. $J$. Endocr. 8, 341-346.

Moore, P.J. \& Greenwald, G.S. (1974) Effect of hypophysectomy and gonadotropin treatment on follicular development and ovulation in the hamster. Am. J. Anat. 139, 37-48.

Murr, S.M., Geschwind, I.I. \& Bradford, G.E. (1973)
Plasma LH and FSH during different oestrous cycle conditions in mice. J. Reprod. Fert. 32, 221-230.

Pedersen, T. (1970) Follicle kinetics in the ovary of the cyclic mouse. Acta endocr., Copenh. 64, 304-323.

Richards, J.S. (1975) Estradiol receptor content in rat granulosa cells during follicular development: modification by estradiol and gonadotropins. Endocrinology 97, 1174-1184.

Richards, J.S. (1980) Maturation of ovarian follicles: actions and interactions of pituitary and ovarian hormones on follicular cell differentiation. Physiol. Rev. 60, 51-89.

Schwartz, N.B. (1974) The role of FSH and LH and of their antibodies on follicle growth and on ovulation. Biol. Reprod. 10, 236-272.

Tsafriri, A. \& Kraicer, P.F. (1972) The time sequence of ovum maturation in the rat. $J$. Reprod. Fert. 29, 387-393.

Tsafriri, A., Pomerantz, S.H. \& Channing, C.P. (1976) 
Inhibition of oocyte maturation by porcine follicular fluid: partial characterization of the inhibitor. Biol. Reprod. 14, 511-516.

Welschen, R. Dullaart, J. (1976) Administration of antiserum against ovine follicle-stimulating hormone or ovine luteinizing hormone at pro-oestrus in the rat: effects on follicular development during the oncoming cycle. J. Endocr. 70, 301-306.

Yanal, R. \& Nagasawa, H. (1974) Radioimmunoassay of pituitary and plasma prolactin during the oestrous cycle in mice. J. Endocr. 62, 685-686.

Received 16 March 1981 